создавать благоприятные условия для ее развития. В дальнейшем исследование будет нацелено на осуществление анализа педагогических условий развития музыкальной памяти личности младшего школьника, а также на определение эмоций и мотивации личности в мнемической системе ученика начальных классов.

Ключевые слова: музыкальная память, психическое развитие, мнемическая деятельность, механический характер памяти, логическая память, произвольное запоминание.

Iryna Rozhko, post-graduate student, Department of Methods of Music Education, Vocals and Choral Conducting, Sumy State A.S. Makarenko Pedagogical University, music teacher of Higher Municipal Educational Institution of Sumy Regional Counsil «Lebedinsky A.S. Makarenko Pedagogical College», 73, Lenina Str., Lebedin, Ukraine.

\title{
SCIENTIFIC APPROACHES TO PRIMARY SCHOOL STUDENTS' MUSICAL MEMORY DEVELOPMENT
}

The role of cognitive processes in the implementation of the musical activities of pupils is a topical issue of theory and methods of contemporary music education. The perception, thinking, imagination, attention, and memory of primary school students, their psychological experience, emotional, motivational, and other spheres of life has its own significant features different from the corresponding aspects of adults' psyche. Primary school age is considered to be the most favourable for the musical memory development by a variety of psycho-physiological and educational factors. The functioning of musical memory, the specifics of mnemonic processes (memory, storage, playback, remembering, forgetting) are special for different age groups of pupils and for various acts in Music lessons. The analysis and comparison of existing approaches to the definition of the characteristics of primary school students' memory have been presented in the article. The essence of the concepts of «mechanical nature of memory», «logical memory», «spontaneous memorization» have been described there. The author emphasizes the importance of conscious memorization of musical material, compares the performance of voluntary and involuntary memory, dependant from the organization of mnemonic activity. The author proves the feasibility of the development of the spontaneous type of music material memorization. The practical significance of the study is the generalization of the advanced pedagogical experience in the issue of musical memory development. Memory is one of the central and basic mental functions in early childhood. The problem of the development of memory is important in contemporary music education. The further researches will be focused on the analysis of the pedagogical conditions of the musical memory development in primary school students, and also on the examination of emotions and motivation of personality in mnemonic system of primary school students.

Keywords: musical memory, psychological development, mnemonic activity, mechanical nature of memory, logical memory, spontaneous memorization.

Подано до редакиіiі 15.01.2016

Рецензент: д. пед. н., проф. О. В. Лобова

УДК: $378.1+37.03 .42$

Максим Борисович Імерідзе, аспірант кафедри педагогіки, Південноукраїнський національний педагогічний університет імені К. Д. Уиинського, вул. Старопортофранківська, 26, м. Одеса, Україна

\section{РЕАЛІЗАЦІЯ ЕКСПЕРИМЕНТАЛЬНОЇ МОДЕЛІ ФОРМУВАННЯ МЕДІАОСВІТНЬОЇ КОМПЕТЕНТНОСТІ МАЙБУТНІХ УЧИТЕЛІВ} \footnotetext{
чні технологї, навчальні технологї, мас-медіа.

Постановка проблеми. Освітній простір держави як невід'ємна складова загального соціального простору зазнав трансформацій у зв'язку з кардинальною зміною функціональних позицій сучасного вчителя як суб'єкта професійно-педагогічної діяльності. Традиційні підходи до підготовки вчителів у ви-
}

У статті висвітлено експериментальну модель формування медіаосвітньоїкомпетентності, особливості проблеми інтеграції освіти й інформаційно-комунікаційних технологій. Крім того, проаналізовано иляхи визначення рівня обізнаності з медіаосвіти фахівиів у провідних вищчи навчальних закладах.

Ключові слова: медіа, медіаосвіта, медіакомпетентність, комп'ютерний підхід, превентивний, педагогі-

шах не враховують стрімких, швидкоплинних процесів, що характеризують сучасні вимоги до підготовки компетентного випускника будь-якого навчального закладу. Зокрема, сучасний фахівець має бути озброєний арсеналом засобів входження у віртуальний освітній простір, володіти інструментарієм для вільного 
користування інформаційними ресурсами, свідомо застосовувати превентивні засоби інформаційної безпеки, ураховувати специфіку функціонування сучасного медіапростору тощо.

Відтак, професійна компетентність випускника педагогічного вишу повинна характеризуватися наявністю спеціальної компоненти, що забезпечує стратегію ефективного використання потенціалу медіапростору в контексті професійно-педагогічної діяльності.

Аналіз останніх публікацій. Аналіз наукової літератури засвідчує наявність різних підходів до визначення сутності медіаосвіти: навчання теорії та практичних умінь щодо оволодіння сучасними засобами масової комунікації (документи ЮНЕСКО); вивчення ключових понять: «джерело медіаінформації», «категорії медіа», «технології медіа», «медіамова», «аудиторія медіа», «репрезентації медіа» (К. Безелгет i Е. Харт); медіаосвіта як громадянське виховання (Ж. Гоне), як формування медіаграмотності (Р. К'юбі, К. Тайнер та ін.) [6]; процес освіти й розвитку особистості за допомогою й на матеріалі засобів масової комунікації (медіа) з метою формування культури спілкування 3 медіа, творчих, комунікативних здібностей, критичного мислення, умінь інтерпретації, аналізу й оцінки медіатексту (Ю. Усов, О. Федоров); вивчення закономірностей створення, сприйняття й споживання текстів 3МI, ролі засобів масової комунікації у формуванні комунікативної, інформаційної, соціальної, естетичної культури людини (Н. Леготіна), соціалізація молоді засобами ЗМІ (С. Курліщук) тощо [1].

Мета статті полягає у презентації експериментальної моделі формування медіаосвітньої компетентності майбутніх учителів.

Виклад основного матеріалу. Конструювання модельного відображення процесу формування медіаосвітньоїі компетентності майбутніх учителів в освітньому середовищі університету полягає у накресленні основних цільових орієнтирів дослідноекспериментальної роботи, а саме: мети та прогнозованого результату формувальної роботи, змістових ліній здійснення експериментальних заходів, форм та методів аудиторної та виховної роботи зі студентами.

Модель (франц. modele, від лат. modulus - зображення) - це схема, графік будь-якого об'єкта, процесу або явища, що використовується як спрощена його заміна.

Загальнонаукову проблематику ідеальної типології моделей та концептуальних засад наукового моделювання фундаментально досліджено в науковому доробку В. Штоффа. Категорію «модель» учений тлумачить як певну систему, що реально існує або є мисленнєво уявною [5]. Система-оригінал та система-дублікат $є$ ізоморфними за структурою, що дозволяє транспонувати результати дослідження особливостей системи-дубліката на систему-оригінал. Моделювання передбачає конструювання моделі-дубліката, що відтворює функціональні особливості структури, динаміку поведінки та інші властивості моделі- оригінала та експериментальне або мисленнєве дослідження цієї моделі. Водночас доведено, що моделі можуть бути як матеріальними, так і мисленнєвими (уявними) [3].

Суголосну думку висловлює В. Краєвський, зауважуючи, що модель $є$ системою елементів, яка відтворює певні сторони, зв'язки, функції предмету дослідження, тобто оригінала. Вона слугує узагальненим віддзеркаленням явища, результатом абстрактного узагальнення практичного досвіду, а не безпосереднім результатом експерименту [6].

Під моделюванням у педагогіці розуміється дослідження педагогічних та психолого-педагогічних процесів і станів за допомогою ідеальних моделей. Педагогічне моделювання (за С. Гончаренком) [4] $є$ науково обгрунтованим конструюванням, що відповідає заданим вимогам і накресленій до побудови в близькому або віддаленому майбутньому моделі досліджуваного педагогічного процесу, ізоморфної реальному об'єктові з точки зору властивостей, які вивчаються у педагогічному експерименті. У зв'язку 3 цим, метою педагогічного моделювання $є$ виявлення можливостей удосконалення навчально-виховного процесу, пошуку резервів підвищення його ефективності і якості на основі аналізу моделі. Предметом аналізу, спираючись на вищезазначене, $є$ сукупність взаємовідносин і зв'язків суб'єктів освітнього процесу, об'єднаних загальною метою функціонування i єдності управління.

Продуктивною в аспекті дослідження є позиція С. Гончаренка [4], відповідно до якої моделювання має винятково важливе значення для спрямування, організації діяльності та постановки конкретних завдань, оскільки метою моделювання є передбачення у свідомості результату, на здобуття якого спрямована діяльність, а категорія «мета» у вигляді логічної моделі фіксує бажане.

Проте, систематизація основних елементів (компонентів, структурних блоків) дозволяє розкрити лише структуру, що є лише статичним представленням педагогічної системи. На відміну від властивості, функція констатує момент прояву якості відносно зовнішнього середовища. У філософському сенсі функція або функціональний аналіз якості виявляє доцільність, ефективність іiі існування відносно інших якостей, які знаходяться в її оточенні, поза межами їі власної якісної визначеності. На відміну від властивості, що визначає усталеність стану якості, функції виявляють простір, де означена усталеність взаємодіє 3 іншими ефективно. Таким чином, динаміку системи дозволяє висвітлити лише іiі функціональний аналіз, тобто встановлення функціонального відношення між цілісною структурою та іiі підструктурами, встановлення функціональних зв'язків між елементами системи, з'ясування міри значущості кожного окремого елементу (блоку) для збереження цілісності, усталеності та динамічного розвитку [2]. 
Експериментальна модель формування медіаосвітньої компетентності майбутніх учителів включає такі компоненти:

- цільовий компонент, який відображає мету формування медіаосвітньої компетентності майбутніх учителів;

- функиіональний компонент, змістове ядро якого складають педагогічні умови, що забезпечують формування медіаосвітньої компетентності майбутніх учителів;

- результативний компонент (результат - сформованість медіаосвітньої компетентності майбутніх учителів).

Упровадження експериментальної моделі формування медіаосвітньої компетентності студентів здійснювалося в межах навчально-виховного процесу факультетів (історико-філософське відділення, інститут мов світу (спеціальність - українська мова та література, англійська мова) Південноукраїнський національний педагогічний університет імені К. Д. Ушинського) та в межах проведення спеціального курсу для студентів «Основи формування медіаосвітньої компетентності сучасного вчителя».

Впровадження експериментальної моделі здійснювалось шляхом реалізації педагогічних умов, що забезпечують формування медіаосвітньої компетентності студентів - майбутніх учителів суспільногуманітарного профілю:

$>$ стимулювання мотиваційної настанови студентів на застосування елементів медіа у професійній діяльності;

$>$ систематизацію знань студентів щодо феномену «медіаосвіта»;

$>$ набуття досвіду впровадження медіаосвітніх технологій у професійній діяльності.

Експериментальну модель було впроваджено в навчально-виховний процес за трьома етапами: інформаційно-збагачувальним, мотиваційно-настановним та практико-орієнтованим етапами.

На першому - інформаційно-збагачувальному етапі реалізовувалась переважно педагогічна умова «систематизація та узагальнення знань студентів щодо феномену «медіаосвіта»»).

Метою цього етапу було відображення у змісті нормативних дисциплін сутності та потенціалу медіаосвіти, демонстрація іiі значущості в професійній діяльності. Задля цього навчальний матеріал дисциплін «Педагогіка», «Педагогіка вищої школи», «Методика виховної роботи», «Інформатика» було збагачено інформацією щодо можливостей медіатехнологій, засобів удосконалення навчального процесу школи елементами медіаосвіти. Крім того, реалізації цієі умови було присвячено другий змістовий модуль розробленого спецкурсу.

На мотивачійно-настановному етапі впровадження експериментальної моделі переважно реалізовувалась педагогічна умова «стимулювання мотива- ційної настанови студентів на застосування медіаосвітніх технологій у професійній діяльності».

Метою практико-орієнтованого етапу впровадження експериментальної моделі було практичне засвоєння та відпрацювання студентами - майбутніми учителями суспільно-гуманітарних дисциплін моделей використання потенціалу медіаосвіти в системі професійної діяльності. На цьому етапі переважно реалізовувалася педагогічна умова «набуття досвіду впровадження медіаосвітніх технологій у майбутній професійній діяльності».

Для проведення експерименту було розроблено спецкурс для студентів «Основи формування медіаосвітньої компетентності студентів гуманітарних дисциплін». Навчальний курс складався з 60 годин та містив лекційні, семінарсько-практичні заняття. Крім того, було розроблено систему самостійних індивідуально-дослідних проектів для студентів.

Спецкурс складався 3 трьох змістових модулів, змістове навантаження кожного 3 яких розкривало зміст визначених педагогічних умов та етапів. Перший змістовий модуль «Освітні виміри стратегії реалізації медіаосвіти в Україні» було розроблено 3 метою визначення освітнього потенціалу сучасних медіаосвітніх технологій, встановлення термінологічних меж феномену «медіаосвіта», визначення дефінітивного різноманіття визначень та понять проблематики у сучасних науково-педагогічних дослідженнях.

Другий модуль спецкурсу - «Медіатизачія професійної діяльності вчителя суспільно-гуманітарного профілю» - розкривав особливості використання медіаосвітніх технологій сучасними вчителями, зокрема висвітлював, якими особистісними характеристиками має володіти вчитель для ефективного впровадження медіаосвітніх технологій у професійній діяльності. Крім того, студенти дізнавались, які спеціальні вміння забезпечують формування медіаосвітньої компетентності, які для цього повинні бути сформовані знання. Провідним аспектом модулю було усвідомлення вчителями необхідності впровадження медіаосвітніх технологій саме вчителями суспільно-гуманітарного профілю. Відтак, майбутні вчителі вчились послуговуватись медіаосвітніми технологіями відповідно до специфіки майбутньої професійної діяльності - вчителя суспільно-гуманітарних дисциплін.

Третій модуль спецкурсу - «Практична медіалогія у професійній діяльності сучасного вчителя суспільно-гуманітарного напряму» мав на меті практичне відпрацювання студентами-майбутніми учителями суспільно-гуманітарних дисциплін навичок послуговування медіаосвітніми технологіями. Для цього було розроблено серію завдань, які розкривали прикладні аспекти маедіаосвітньої компетентності майбутнього вчителя відповідно до специфіки дисциплін у школі.

Висновки. Визначено, що медіаосвітня компетентність учителя суспільно-гуманітарного профілю це складний професійно-особистісний конструкт, що забезпечує розуміння особистістю педагога соціоку- 
льтурного, економічного і політичного контексту функціонування медіа, відображає його прагнення та здатність бути носієм і транслятором медіакультурних стандартів, ефективно взаємодіяти з освітнім медіапростором, відтворювати та виробляти нові елементи медіакультури сучасного суспільства.

Аналіз наукових джерел дозволив конкретизувати модель формування медіаосвітньої компетентності як частину освітнього процесу, спрямовану на форму-

\section{ЛІТЕРАТУРА}

1. Немов Р. С. Психология : словарь-справочник : в 2-х частях / Р. С. Немов. - М. : ВЛАДОС-ПРЕСС, 2003- Ч. 2. - 2003. - 352 c.

2. Неперервна професійна освіта: проблеми, пошуки, перспективи: Монографія / За ред. I. А. Зязюна. - К.: Віпол, 2000. - 636 с.

3. Неперервна професійна освіта: філософія, педагогічні парадигми, прогноз: Монографія / В. П. Андрущенко, I. А. Зязюн, В. Г. Кремень, С. Д. Максименко, Н. Г. Ничкало, С. О. Сисоєва, Я. В. Цехмістер, О. В. Чалий / За ред. В. Г. Кременя. К.: Наукова думка, 2003. - 853 с.

4. Гончаренко С. У. Український педагогічний енциклопедичний словник. Видання друк, доповнене

\section{REFERENCES}

1. Nemov, R. S. (2003). Psikhologiya: slovarspravochnik : v 2-kh chastyakh [Psychology: Glossary: in 2 parts]. Moscow: VLADOS PRESS [in Russian].

2. Zyazyun, I. A. (Ed.). (2000). Neperervna profesiina osvita: problemy, poshuky, perspektyvy: Monohrafiia [Continuing professional education: problems, searches, prospects: Monograph]. Kyiv: Vipol [in Ukrainian].

3. Andruschenko, V. P., Zyazyun, I. A., Flint, V. G., Maksimenko, S. D. (et al.). (2003). Neperervna profesiina osvita: filosofiia, pedahohichni paradyhmy, prohnoz: Monohrafiia [Continuous professional education, philosophy, pedagogical paradigm forecast: Monograph]. Kremen, V. G. (Ed.). Kyiv: Naukova Dumka [in Ukrainian].

4. Goncharenko, S. U. (2011). Ukrainskyi pedahohichnyi entsyklopedychnyi slovnyk [Ukrainian вання в суспільстві медіа-культури, підготовку особистості до безпечної та ефективної взаємодії із сучасною системою мас-медіа, включаючи як традиційні (друковані видання, радіо, кіно, телебачення), так і новітні (комп'ютерно опосередковане спілкування, інтернет, мобільна телефонія) медіа 3 урахуванням розвитку інформаційно-комунікаційних технологій; розуміння видів медіа та їх впливу на людину і суспільство)

й виправлене / С. У. Гончаренко. - Рівне: Волинські обереги, 2011. - 552 с.

5. Гриневич, М. Стимулюємо аналітичні здібності медіа-освіти. Квести як засіб формування критичного мислення студентів мистецьких спеціальностей в процесі вивчення курсу «Основи медіакультури» / М. Гриневич // Освіта. - 2010. №13-14 (17-24 березня). - С. 7-8.

6. Медіаосвіта та медіаграмотність: підручник / Ред.-упор. В. Ф. Іванов, О. В. Волошенюк; За науковою редакцією В. В. Різуна. - Київ: Центр вільної преси, 2012. - 352 с.

Pedagogical Encyclopedic Dictionary]. $2^{\text {nd }}$ ed. rev. Rivne: Volynski oberehy [in Ukrainian].

5. Hrynevych, M. (2010). Stymuliuiemo analitychni zdibnosti media-osvity. Kvesty yak zasib formuvannia krytychnoho myslennia studentiv mystetskykh spetsialnostei v protsesi vyvchennia kursu «Osnovy mediakultury» [Stimulating analytical skills of media education. Quests as as a form of critical thinking of students of art specialties in the study course "Basics of media culture"]. Osvita Education, 13-14, 7-8 [in Ukrainian].

6. Ivanov, V. F., Voloshenyuk, O. V. (2012). Mediaosvita ta mediahramotnist: pidruchnyk [Media Education and mediacompetence: textbook]. Rizun, V. V. (Ed.). Kyiv [in Ukrainian].

Максим Борисович Имеридзе, аспирант кафедры педагогики, Южноукраинский национальный педагогический университет имени К. Д. Уиинского, ул. Старопортофранковская, 26, г. Одесса, Украина

\section{РЕАЛИЗАЦИЯ ЭКСПЕРИМЕНТАЛЬНОЙ МОДЕЛИ ФОРМИРОВАНИЯ МЕДИАОБРАЗОВАТЕЛЬНОЙ КОМПЕТЕНТНОСТИ БУДУЩИХ УЧИТЕЛЕЙ}

Учителя применяют мультимедийные технологии в процессе подготовки к занятию, а также изучая опыт коллег, в процессе самообразования, электронных работ авторов, для организации работы учащихся в интернетлабораториях; проведения онлайн тематического или текущего контроля знаний, для применения в стационарной подготовке элементов дистанционного обучения, вовлечению учащихся к выполнению задач творческого или исследовательского характера, которые обеспечивают поиск информации в Интернете, создание собственных блогов и веб-сайтов, участие в телекоммуникационных проектах, сетевых конкурсах и так далее. Необходимым условием моделирования является продвижение фундаментальной идеи, способной развить компетентность. Знания и умения 
являются эффективными устройствами мышления, если в сознании учеников (студентов) они организованы в системе взаимосвязанных понятий. Моделирование компетентности медиаобразования зависит от порядка их изучения (наряду с учетом психологии и педагогических требований к процессу ассимиляции). Таким образом, высокий уровень усвоения знаний означает возможность студента свободно применять эти знания в различных условиях. Определено, что медиаобразовательная компетентность преподавателей социальных и гуманитарных наук - это сложный профессиональный конструкт, который дает понимание личностью учителя социально-культурного, экономического и политического контекста функционирования СМИ, отражает его желание и способность быть эффективным носителем медиакультурных стандартов в образовательном медиапространстве, создавать новые элементы медиакультуры современного общества. Анализ научных источников позволяет конкретизировать точную модель медиакомпетентности в рамках образовательного процесса, направленного на создание социальной культуры средств массовой информации, подготовки человека к безопасному и эффективному взаимодействию с современными средствами массовой информации, в том числе традиционными (печатные издания, радио, кино, телевидение) и новыми (компьютерной связи, интернет, мобильная телефония) средствами массовой информации с развитием информационных и коммуникационных технологий; понимание типов носителей и их воздействие на людей и общества в целом).

Ключевые слова: медиа, медиаобразование, медиакомпетентность, компьютерный подход, превентивный, педагогические технологии, обучающие технологии, масс-медиа.

\section{Maksym Imeridze, post-graduate student, Department of pedagogy, South Ukrainian National Pedagogical University named after K. D. Ushinsky, 26, Staroportofrankivska Str., Odesa, Ukraine}

\section{IMPLEMENTATION OF THE EXPERIMENTAL MODEL OF FUTURE TEACHERS' MEDIA EDUCATION COMPETENCE FORMATION}

The article presents the experimental model of future teachers' media education competence formation. Teachers use media technologies when preparing for lessons, studying the experience of their colleagues, self-educating, exploring the content of other authors' works, organizing work of pupils in online laboratories; carrying out online academic performance ratings, encouraging pupils to perform creative tasks which provide information search in the Internet, creation of own blogs and websites, participation in telecommunication projects, network competitions and so forth. The promotion of a fundamental idea able to develop media competence is considered to be a necessary condition of modelling. Knowledge and abilities are the effective device of thinking if they are organized in the system of interconnected concepts in students' consciousness. Therefore, the high level of knowledge acquisition means students' ability to freely apply this knowledge under various conditions. It has been determined that the media-educational competence of teachers of social studies and humanities is a complex professional construct providing their understanding of sociocultural, economic and political peculiarities of media functioning, reflecting their desire and ability to be bearers of mediacultural standards in educational media space, play and produce new elements of media culture in the modern society. The review of scientific sources allows to justify the model of Media-competence as part of the educational process, aimed at developing social media culture, preparing a person for safe and effective interaction with modern media, including traditional (print, radio, cinema, television) and innovative (computer-mediated communication, Internet, mobile telephony) forms with the development of information and communication technologies; understanding the types of media and their impact on people and the society.

Keywords: media, media education, mediacompetence, computer approach, preventive, educational technology, educational technology, mass-media.

Реиензент: д. пед. н., проф. Г. Х. Яворська

Подано до редакиії 15.01.2016 